\title{
Nutritional status in older adults across care settings
}

\author{
N. Omar, M. Gibbs and K. Hart \\ Division of Nutritional Sciences, Faculty of Health and Medical Sciences, University of Surrey, Guildford, GU2 7XH, UK
}

Malnutrition is a serious and common problem in older adults with a reported prevalence in UK hospitalised older adults (over 75 years) of $21 \%{ }^{(1)}$. The aim of this study was to determine the nutritional status and factors affecting satisfaction with food-related quality of life in older adults in different care settings; free-living, care home and hospital.

Seventy six older adults aged 75 years old and over were recruited to an observational study from their own homes, 3 day centers, 4 sheltered housing sites, 4 care homes and a hospital in Surrey. Each subject was visited twice to complete the Mini Nutritional Assessment (MNA), the Satisfaction with Food-related Life (SWFL) questionnaire ${ }^{(2)}$ and three 24 hr diet recalls. The data were analysed with Dietplan 6 and SPSS (v16).

MNA results showed that $15 \%$ of the free-living sample were malnourished, $13 \%$ from care homes and $24 \%$ of the hospitals sample, with no significant different in total MNA scores between care settings $(p>0.05)$ [see table 1], nor in the prevalence of malnutrition $(p=0.19)$.

Table 1. Anthropometrics and MNA results for older adults across care settings.

\begin{tabular}{|c|c|c|c|c|c|c|c|}
\hline & \multicolumn{2}{|c|}{ Free-living $(n=27)$} & \multicolumn{2}{|c|}{ Care home $(n=24)$} & \multicolumn{2}{|c|}{ Hospital $(n=25)$} & \multirow[b]{2}{*}{$P$ value } \\
\hline & Mean & $\mathrm{SD}$ & Mean & $\mathrm{SD}$ & Mean & $\mathrm{SD}$ & \\
\hline Age (years) & 83 & 6.7 & 87.9 & 6.8 & 84 & 5.8 & 0.02 \\
\hline BMI $\left(\mathrm{kg} / \mathrm{m}^{2}\right)$ & 25.9 & 5.2 & 24.5 & 4.1 & 22.5 & 4.7 & 0.03 \\
\hline Weight $(\mathrm{kg})$ & 70.8 & 20.8 & 67.5 & 13.1 & 67.2 & 15.6 & 0.90 \\
\hline Height (m) & 1.6 & 0.1 & 1.6 & 0.1 & 1.7 & 0.1 & 0.02 \\
\hline MNA score $(\max =30)$ & 22.4 & 6.3 & 21.7 & 4.5 & 19.4 & 5.5 & 0.07 \\
\hline
\end{tabular}

Significant differences were found between care settings for individual MNA items: including the presence of neuropsychological problems $(p=0.048)$, use of prescribed drugs $(p=0.04)$, total number of meals/day $(p<0.0005)$, estimated protein and fruit and vegetable intakes $(p<0.0005 \& 0.039)$, and comparative health status with others $(p=0.037)$. Dietary recalls suggested significant differences in nutrient intakes across settings but not between genders. Risk of malnutrition (as assessed by total MNA score) was significantly correlated with intakes of energy $(r=0.5)$, protein $(r=0.49)$, fat $(r=0.25)$ and carbohydrate $(r=0.54)$ whilst number of meals per day was a significant predictor of energy intake $(r=0.134)$. Multiple regression analysis by setting suggested that independence, use of prescription drugs, total number of meals/day and protein and fluid intakes were the primary predictors of malnutrition in free-living older adults, whilst for those in care, appetite (care homes) and nutrient intakes and disease-related stress (hospitals) were of greater importance.

Whilst some of the findings, such as the importance of adequate energy and protein intakes for malnutrition risk, were expected this study has highlighted the importance of additional, often overlooked issues such as satisfaction with food. It also suggests that the correlates of malnutrition in older adults may be setting-dependent helping to inform future prevention strategies in the growing population of older adults.

1. Margetts et al. (2003) Prevalence of risk of undernutrition is associated with poor health status in older people in the UK. European Journal of Clinical Nutrition 57, 69-74.

2. Grunert et al. (2007) A measure of satisfaction with food-related life. Appetite 49, 486-493. 